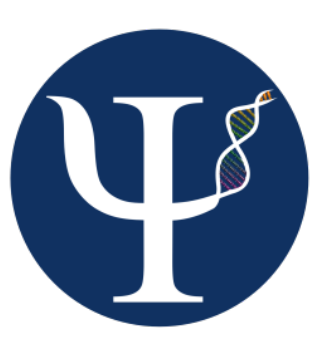

\title{
Mothers' depression and stress, severity of autism among children and family income
}

Estrés y depresión en madres, severidad de autismo en niños e ingresos familiares

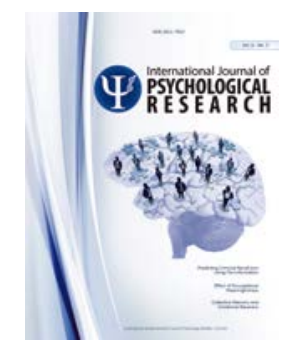

R e s e a r h

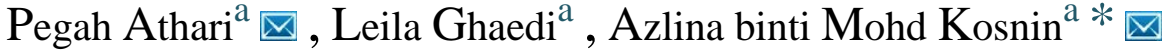 \\ a Department of educational psychology, Faculty of Education Universiti Teknologi Malaysia
}

Article History:

ARTICLE INFO

Received: 31-08-2013

Revised: 15-11-2013

Accepted: 4-12-2013

\section{ABSTRACT}

This study was conducted to investigate the relationship between mothers' depression and stress compared with severity of autism in children and the effect of family income on the relationship between these two latter variables. Levels of depression and stress among mothers $(n=250)$ were measured based on Depression Anxiety and Stress Scale of 42 items (DASS $\neg-42$ ). The severity of autism among children was assessed by Autism Behavior Checklist (ABC) according to children's teachers reports $(n=250)$. Family income was recorded based on mothers' report and it was investigated as a mediator for the relationship between mothers' depression-stress and severity of autism among children. Results showed that different incomes of mothers have significant effect on the level of depression and stress among mothers and the severity of autism; besides, results indicated that severity of autism in children changes with family income and mothers' depression and stress-severity.

\section{RESUMEN}

Este estudio fue conducido para investigar la relación entre depresión y estrés de madres comparados con la severidad de autismo en niños y el efecto de los ingresos familiares sobre una relación entre estas dos variables. Los niveles de estrés y depresión entre las madres $(n=250)$ fueron medidos usando la escala de presión, ansiedad y estrés de 42 ítems (Depression Anxiety and Stress Scale of 42 ítems, DASS $\neg-42)$. La severidad de autismo de los niños fue evaluada con la lista de comportamientos autistas (Autism Behavior Checklist, ABC) de acuerdo a los reportes de los profesores $(n=250)$. Los ingresos familiares fueron incluidos de acuerdo al reporte de las madres y fueron investigados como medidores de la relación entre depresión-estrés de madres y la severidad de autismo entre los niños. Los resultados mostraron que los diferentes ingresos de las madres tienen un efecto significativo en el nivel de depresión y estrés de las madres y la severidad del autismo; además los resultados también indicaron que la severidad del autismo cambia con los ingresos familiares y los niveles de depresión y estrés de las madres.
Key Words:

Autism in Children, Mothers'

Depression, Mothers' Stress, Family Income
Palabras Clave:

Autismo Infantil, Depresión Maternal, Estrés Materno, Ingresos Familiares

\footnotetext{
* Corresponding author: Pegah Athari, Department of educational psychology, Faculty of Education Universiti Teknologi Malaysia, 81310 UTM Johor Bahru, Malaysia, Email: pegah.athari.1@gmail.com
} 


\section{INTRODUCTION}

Autism and four other disorders, Asperger disorder, Rett disorder, Childhood Disintegrative Disorder, and Pervasive Developmental Disorder Not Otherwise Specified (PDDNOS), are classified in a group of disorders entitled Pervasive Developmental Disorders (PDD) (Buitelaar, Van der Gaag, Klin, \& Volkmar, 1999). Based on research, autism is considering a growing concern; however, in different countries and in different decades the prevalence of autism was reported differently. Consequently, based on Lin, Lin, and Wu (2009), the prevalence of autism was reported 5.2 out of 10000 from 1966 to 1998; however, this amount has recently increased to 1 out of 150. Also, Matson and Kozlowski (2011) indicated an increased number of autism case among children in Norway, Canada, Iran, United States of America, United Arab Emirate, France, Iceland, Germany, Finland, Israel, and Britain from 1997 to 2011. In accordance with previous research, the prevalence of autism was reported by Mohammadi, Salmanian, \& Akhondzadeh (2011) as, 19 per 1000 children in Iran.

On the other hand, depression and stress were considered as common disorders among mothers' of children with autism (Benson, 2006, 2010; Benson and Karlof, 2009). Also, it is mentioned that although depression and stress are distinct, they often co-occur (Barlow and Durand, 2012; Shamsuddin et al., 2013). Consequently, based on the importance and high prevalence of autism among children and depression and stress among mothers, several researches have been done to correlate the relationship between them.

Based on Milgrom, Schembri, Ericksen, Ross, \& Gemmill (2011), depression and stress during and after pregnancy have a negative effect on both the fetus and the child, as well as both depression and stress after pregnancy cause a poor mother-infant relationship, leading to poor cognitive and behavioral development in the child (Milgrom et al., 2011). The effect of depression and stress has become significant to children who are diagnosed with autism and the effect of these factors during pregnancy can lead to Autistic Disorder or increase the symptoms of Autistic Disorder after pregnancy (Kinney, Munir, Crowley, \& Miller, 2008). Based on research (Korosi et al., 2012; Levy \& O'Hara, 2010; Turney, 2012) mothers' depression and stress have long lasting effects on cognitive, behavioral, and health outcomes. This emotional disorder of mother affects children from infancy through adulthood, especially during the first 12 months after the child birth as these extra deficits are compounded by inborn cognitive, behavioral, and health problems. The negative effects are mentioned in previous research: cognitive problems such as lower IQ and attention scores compared to their peers, behavioral problems such as externalizing behavior, antisocial behavior, reduced communication skills including speechlessness and a total disconnection from environment problems and emotional problems such as feeling depressed and isolated (Essex, Klein, Cho, \& Kalin, 2002; Ethier, Lacharite and Couture, 1995; Keen, Couzens, Muspratt, \& Rodger, 2010; Osborne, McHugh, Saunders, \& Reed, 2008; Yozwiak, 2010).

There are some other researches related to the effects of the severity of autism among children based on the level of depression and stress among their mothers and the effect of mother's depression and stress on the fetus and the relevance of autism rising (Kinney et al., 2008; Previc, 2007; Tsai, Tsai, \& Shyu, 2008). Thus, the question arises; what is the influence of depression and stress among mothers on the severity of autism in their children? Accordingly, one part of this research is dedicated to the relationship between the severity of autism among children and the level of depression and stress in mothers. The predictability of autism based on depression and stress is also part of this research.

Based on the objectives of this study, family income was also considered and indicated to affect the whole family, specifically the children; moreover, (Papalia \& Feldman, 2012) mentioned the effect on emotional and behavioral welfare and family income on the whole family and children respectively. There are several studies about the family income (Dohrenwend, 1990; Keenan, Gunthorpe, \& Grace, 2007; Santiago, Wadsworth and Stump, 2011). Based on (Dohrenwend, 1990), low family income is the reason for several disorders such as schizophrenia, and personality disorders, depression and stress. Furthermore, (Wadsworth et al., 2008) mentioned low income as a fundamental reason for psychological health disorders, a range of psychopathology disorders and some mental health disorders, especially depression (Inaba et al., 2005; Levy and O'Hara , 2010). Additionally, (Keenan, Gunthorpe, \& Grace, 2007) indicated low socioeconomic status and low income as first stressors in poor families and poor psychological health with internalizing and externalizing symptoms, which are depression, anxiety, and attention problems respectively and are considered as the second stressors caused by the first ones.

According to several research conducted, low family income has an effect on the individual's physical and emotional status and are causing psychiatric 
disorders, difficulties in connective functions, and changes in the brain's structure during childhood (Korosi et al., 2012; Lupien, King, Meaney, \& McEwen et al., 2000). The report (Oregon Health \& Science University family physician, 2011) also indicated that low family income has side effects on families and children with autism such as difficulties in accessibility to medical opportunities and the way the staff treat these families. Consequently these families bear excessive stressors that are caused by the environment, and severe level of disability in their children is made worse by the lack of adequate facilities. Thus, based on the importance of variables mentioned in this research, five objectives were mentioned:

- $\quad$ To identify the relationship between the level of depression and stress among mothers and the severity of autism in their children.

- To identify the relationship between family income and the level of depression and stress among mothers.

- To identify the relationship between family income and the severity of autism among children.

- To identify the contribution of the severity of autism in children to the level of depression and stress among mothers.

- $\quad$ To identify the role of family income as a mediator on the relationship between mothers' depression and stress and the severity of autism among children.

\section{METHOD}

\subsection{Participants and Research design}

In this research, purposive sampling was used in order to collect information from mothers and teachers of children with autism. The aim of using purposive sampling for this study was based on the point that this form of sampling helps to identify important fundamental issues needed to meet the research purpose. Children between the age of 6-8 with autism and their mothers, from special schools and clinics, have been chosen to participate in this research. The mothers and teachers were informed about the purpose of this research and were told that the data provided will be kept confidential and will only be referred for research purpose. The purpose of this research was to collect information from at least 250 mothers of children with autism who were asked to participate; also, teachers of children with autism were asked to fill in questionnaires related to these children. The information about family's income was categorized on reports from "Statistical Center of Iran". Fathers from all families were employed and the family's income was considered without asking about the proportion provided by father or mother.

Correlation design was adopted to fulfill the purposes of this study which pretend to illustrate the relationship between variables, mothers' depression and stress, severity of autism in children, and family income. Also, independent variables (level of depression and stress among mothers and another relationship, family income) were manipulated to illustrate the relationship with dependent variables such as severity of autism in children and another relationship, mothers' depression and stress; Pearson correlation was used to measure the significance of the correlation between independent and dependent variables. Regression coefficient was carried out three times in this research as follows: between mothers' depression and stress and severity of autism among children, between mother's depression and stress and family income, and between the later one and severity of autism among children to identify whether or not family income had a mediating effect on the relationship between the other two variables.

\subsection{Measures}

Two instruments were used in this research. The first instrument was Depression Anxiety Stress Scales (DASS) (Lovibond \& Lovibond, 1995) and the second one was Autism Behavior Checklist (ABC) (Krung, Arick, \& Almond, 1980).

The DASS (Lovibond \& Lovibond, 1995) is a self-report scale consisting of 42 statements to assess depression, anxiety, and stress level with 14 statements for each one. According to the aim of this study, only 28 statements for depression and stress were conducted and participants were asked to choose one item from the 4-point Likert type scale, with 0 indicating "did not apply to me at all", whereas 3 meant "apply to me very much or most of the time".

The ABC (Krung, Arick, \& Almond, 1980) consists of 57 statements for measuring the severity of autism in children. This questionnaire was administered to children's teachers. Teachers chose an item from 1-4 depending on the severity of symptoms they observed in children with autism.

Moreover, Sobel study (Sobel, 1982) was carried out to measure the mediation effect of income on the relationship between the level of depression and stress among mothers (as independent variable) and the severity of autism among children (as dependent variable). According to Sobel test, linear regression was measured for $a, b$, and $c$ relationship as showing in 
Figure 1. These measurements were initially conducted to indicate the significance of the relationship between variables as a pre-requisite element.

\subsection{Data analysis}

In this study, data were analyzed using SPSS 19.0 statistical analysis program. In addition, correlation and regression were carried out to determine the relationship between variables. Cronbach's alpha was measured for correlation study; in this research, Persian version of DASS-42 was employed, and The Cronbach's alpha coefficient indicated 0.930 and 0.928 for each one of the 14 depression and stress statements. This indicates an acceptable internal consistency of instrument. Also, the Persian version of $A B C$ inventory was employed and the 0.894 Cronbach's alpha coefficients were achieved, which indicates acceptable internal consistency of this instrument as well.

\section{RESULTS}

\subsection{Analysis of the relationship between mothers' depression and stress and severity of autism among children and family income \\ The results about the relationship between} mothers' depression, stress and the severity of autism among children indicated that correlation coefficient value was equal to $r=0.809$ and $p$ value $<0.01$ which means it is a statistically significant at the level $p=0.01$ and there is a positive relationship between two variables (Table 1$)$.

\subsection{Analysis of the relationship between family income and mothers' level depression and stress}

The results on the correlation analysis performed on the relationship between family income, depression and stress among mothers indicated that correlation coefficient value was equal to $r=-0.584, r=-$ 0.560 and $r=-0.606$ for each relationship respectively, and the $p$ value $<0.01$ which means it is a statistically significant at the level $p=0.01$, and there is a negative relationship between family income and other variables (Table 2).

\subsection{Analysis of the relationship between family income and the severity of autism among children \\ Negative significant correlation was achieved} between family income and severity of autism among children. The results indicated that correlation coefficient value was equal to -0.606 and the $p$ value $<0.01$ which means it is a statistically significant at the level $p=0.01$, and there is a negative relationship between family income and severity of autism in children (Table 3).

\subsection{Regression test between three variables,} mothers' level of depression and stress, severity of autism among children, and family income

A simple regression was carried out to indicate whether there is a significant relationship between the three variables or not, and to find if in each regression the independent variable can predict the dependent variable. Based on the findings in Table 4, a significant relationship was illustrated for all three relationships. Regression results for depression and stress among mothers and severity of autism in children illustrated that $r^{2}=0.881, p=0.000$ which means it is statistically significant at the level $p=0.01$. Moreover, based on Table $3, r^{2}=0.373, p=0.000$ were achieved for regression correlation between depression and stress among mothers and family income which means that this relationship is significant at the level $p=0.01$. Regression coefficient for family income and severity of autism among children is also demonstrated in Table 3. In this relationship $r^{2}=0.384, p=0.000$ which means it is statistically significant at the level $p=0.01$.

\subsection{Sobel test for mediation}

A mediator is a variable that carries the effect of independent variable to dependent variable (MacKinnon, Warsi, \& Dwyer, 1995), for testing the effect of a mediator three prerequisites are necessary. First, an independent variable should have a significant effect on mediator. Second, a mediator should significantly affect the dependent variable, and last of all, it is required that independent variables have a significant effect on dependent variables without considering the mediator's influence. Accordingly, based on the findings in this research, simple linear regressions indicated statistical significance between three relationships, which are mothers' depression andstress and severity of autism among children, mothers 'depression and stress and family income, and family income and severity of autism among children, as $R$ values of $0.938,0.610$ and 0.620 were achieved for each relationship respectively. In addition, a p-value of 0.000 was attained at level of 0.01 for all these three relations, which means they have a significant relationship. Additionally, t-values in Table 3 prove these significant relationships as well (mothers' depression and stress and severity of autism among children, mothers 'depression and stress and family

| Athari, Ghaedi, \& Mohd Kosnin (2013) | int.j.psychol.res. 6(2) | PP. 98 - 106 | 
income, and family income and severity of autism among children respectively $23.206,-6.584$, and -6.746$)$.

According to Sobel (1982), the variable can be considered as mediator if the Sobel's value is greater than 1.97 (Howell, 2010). Besides, in this study the Sobel's value was achieved 4.80508269 (Two tailed probability of 0.00000155$)$. Based on the findings, family income has the role of mediator for the relationship between mothers' depression and stress and severity of autism among children. This means that by adding family income as a mediator to this relationship, the predictability of dependent variable (severity of autism among children) by means of independent variable (mothers' depression and stress) will be more significant.

\section{DISCUSSION}

This study was conducted to investigate the relationship between the level of depression and stress among mothers and the severity of autism in the children and the effect of family income on this relationship. Moreover, the relationship between family income and mothers' depression and stress and severity of autism was considered as well. These relationships were tackled both from correlation view and regression. This means that the significance of relationships and the predictability of variables were considered.

Consequently, this study had three main conclusions. The first conclusion was based on Pearson coefficient correlation which indicates a strong relationship between depression and stress among mothers and severity of autism in children. These two factors were inversely proportional; if one decreases, the other one increases and vice versa. This means that any factors that lead to an increase in the level of depression and stress among mothers will increase the severity of autism among children and vice versa. This conclusion is in accordance with previous studies such as the study carried out by Osborne et al. (2008) who mentioned that high levels of stress in parents of children with autism will lead to severe levels of autism. Also, based on Levy and O'Hara (2010), mothers' depression may lead to delays in several aspects of their children's lives such as delay in cognitive development. Consequently, based on these findings depression and stress will make the severity of autism get worse since social communication and cognitive difficulties are the main characteristics of this disorder (Miles et al., 2005; Young, Ruble, \& McGrew, 2003); thus, mothers' emotional disorders can negatively affect social, communication and cognitive development in their children.
The second conclusion was based on an investigation into the relationship between the level of depression and stress among mothers and family income. Based on the results, these factors are negatively correlated; that is, a decrease in family income is followed by an increase in depression and stress level in mothers, and rising family income is followed by reductions in the level of depression and stress among mothers. The results of this study follow the research of Santiago et al., (2011) as they mentioned that low SES in families will lead to mental disorders such as depression and stress.

The third conclusion was based on family income and the severity of autism among children. These two factors illustrated the same results as the relationship between mothers' level of depression and stress and family income. Based on the findings, family income and severity of autism in children are negatively correlated, which means that a decrease in one factor is followed by an increase in the other factor and vice versa. These findings were similar to findings in research conducted by Korosi et al. (2012), who indicated that low family income in families is a cause of psychiatric disorders in children. Based on the findings on family income in this research and previous research it was considered an important family health factor that has a direct and indirect influence on family members. As mentioned by family physicians at the Oregon Health \& Science University (2011), low income families faced pressure from staff attitudes and lack of money to provide efficient treatment and therapy for their children. That is why autism is more severe in these cases.

Additionally, the regression coefficients indicated the significant predictability of severity of autism among children based on the level of depression and stress in mothers, meaning that there is a relationship between these two variables and that depression and stress among mothers is a predictor for severity of autism in children. Also, based on Sobel test, family income can be considered as a mediator for mothers' depression and stress and severity of autism among children which means that a family's income status affects the effectiveness of mothers' depression and stress on the severity of autism in children.

Moreover, this study is the first in which family income was considered as the mediator for relationship between mothers' mental health status and severity of autism in children, although the current study has advantages and limitations too. The main instrument for this study was a self-report questionnaire which means that all data were based on participants report. However, if a qualitative method such as interview or observation 
was carried out, further study could illustrate the sources of depression and stress among mothers as well as the duration of these two difficulties, leading to a better understanding of these issues. Additionally, it is preferred to carry out an experimental study, so the casualty between variables can be considered.

\section{CONCLUSION}

On the basis of the findings in this study, there is a significant relationship between the level of depression and stress among mothers and the severity of autism in children. Thus, increasing the level of the three mentioned disorders in mothers allow a higher severity of autism in children. Moreover, family income was considered as a mediator for mother and child relationship, which means that mothers are suffering from depression and stress while they also have low family income and children have a higher level of autism.

\section{REFERENCES}

Barlow, D. H., \& Durand, M. V. (2012). Abnormal Psychology (6 $6^{\text {th }}$ ed.). Belmont, CA: Wadsworth.

Benson, P. R. (2006). The impact of symptom severity of depressed mood in parents of children with ASD: The mediating role of stress proliferation. Journal of Autism and Developmental Disorders, 36, 685-695.

Benson, P. R. (2010). Coping, distress, and well-being in mothers of children with autism. Research in Autism Spectrum Disorders, 4, 217-228.

Benson, P. R., \& Karlof, K. L. (2009). Anger, stress proliferation, and depressed mood in mothers of children with ASD: A longitudinal replication. Journal of Autism and Developmental Disorders, 39, 350-362.

Buitelaar, J. K., Van der Gaag, R., Klin, A., \& Volkmar, F. (1999). Exploring the boundaries of pervasive developmental disorder not otherwise specified: analyses of data from the DSM-IV Autistic Disorder Field Trial. Journal of Autism and Developmental Disorders, 29, 33-43.

Dohrenwend, R. B. (1990). Socioeconomic status (SES) and psychiatric disorders. Are the issues still compelling? Social Psychiatry and Psychiatry Epidemiology, 25, 41-47.

Essex, M. J., Klein, M. J., Cho, E., \& Kalin, N. H. (2002). Maternal Stress Beginning in Infancy May Sensitize Children to Later Stress Exposure: Effects on Cortisol and Behavior. Society of
Biological Psychiatry, 52, 776-784.

Ethier, L. S., Lacharite, C., \& Couture, G. (1995). Childhood adversity, parental stress, and depression of negligent mothers. Child Abuse \& Neglect, 19, 619-632.

Howell, D. C. (2010). Statistical Methods for Psychology ( $7^{\text {th }}$ ed.). Belmont, CA: Wadsworth.

Inaba, A., Thoits, P. A., Ueno, K., Gove, W. R., Evenson, R. J., \& Sloan, M. (2005). Depression in the United States and Japan: Gender, marital status, and SES patterns. Social Science \& Medicine, 61, 2280-2292.

Keen, D., Couzens, D., Muspratt, S., \& Rodger, S. (2010). The effects of a parent-focused intervention for children with a recent diagnosis of autism spectrum disorder on parenting stress and competence. Research in Autism Spectrum Disorders, 4, 229-241.

Keenan, K., Gunthorpe, D., \& Grace, D. (2007). Parsing the relations between SES and stress reactivity: Examining individual differences in neonatal stress response. Infant Behavior \& Development, 30, 134-145.

Kinney, D. K., Munir, K. M., Crowley, D. J., \& Miller, A. M. (2008). Prenatalstress and risk for autism. Neuroscience \& Biobehavioral Reviews, 32, 1519-1532.

Korosi, A., Naninck, E. F. G., Oomen, C. A., Schouten, M., Krugers, H., Fitzsimons, C., \& Lucassen, P. J. (2012). Early-life stress mediated modulation of adult neurogenesis and behavior. Behavioural Brain Research, 227, 400-409.

Krung, D. A., Arick, J., \& Almond, P. (1980). Behavior Checklist for Identifying Severely Handicapped Individuals with High Levels Of Autistic Behavior. Journal of Child Psychology and Psychiatry, 21, 221-229.

Levy, L. B., \& O'Hara, M. W. (2010). Psychotherapeutic interventions for depressed, low-income women: A review of the literature. Clinical Psychology Review, 30, 934-950.

Lin, J. D., Lin, L. P., \& Wu, J. L. (2009). Administrative Prevalence of autism spectrum disorders based on national disability registers in Taiwan. Research in Autism Spectrum, 3, 269-274.

Lovibond, S. H., \& Lovibond, P. F. (1995). Manual for the depression anxiety stress scales. Sydney: Psychology Foundation.

Lupien, S. J., King, S., Meaney, M. J., \& McEwen, B. S. (2000). Child's Stress Hormone Levels Correlate with Mother's Socioeconomic Status and Depressive State. Society of Biological 


\section{International Journal of Psychological Research}

Psychiatry, 48, 976-980.

MacKinnon, D. P., Warsi, G., \& Dwyer, J. H. (1995). A simulation study of mediated effect measures. Multivariate Behavioral Research, 30, 41-62.

Matson, J. L., \& Kozlowski, A. M. (2011). The increasing prevalence of autism spectrum disorders. Research in Autism Spectrum Disorders, 5, 418425.

Miles, J. H., Takahashi, T. N., Bagboy, S., Sahota, P. K., Vaslow, D. F., Hillman, R. E., \& Farmer, J. E. (2005). Essential versus complex autism: definition of fundamental prognostic subtypes. American Journal of Medical Genetics Part A, 135, 171-180.

Milgrom, J., Schembri, C., Ericksen, J., Ross, J., \& Gemmill, A. W. (2011). Towards parenthood: An antenatal intervention to reduce depression, anxiety and parenting difficulties. Journal of Affective Disorder, 130, 385-394.

Mohammadi, M., Salmanian, M., \& Akhondzadeh, S. (2011). Autism Spectrum Disorders in Iran. In M. $\mathrm{R}$, Mohammadi (Ed.), A Comprehensive Book on Autism Spectrum Disorders (pp. 273-182). Retrieved from http://www.intechopen.com

Osborne, L. A., McHugh, L., Saunders, J., \& Reed, P. (2008). The effect of parenting behaviors on subsequent child behavior problems in Autistic Spectrum Conditions. Search in autism spectrum disorders, 2, 249-263.

Papalia, D. E., \& Feldman, R. D. (2012). Experience Human Development (12th ed). New York: Mc Graw Hill.

Previc, F. H. (2007). Prenatal influences on brain dopamine and their relevance to the rising incidence of autism. Prenatal influences on brain dopamine and their relevance to the rising incidence of autism. Medical Hypotheses, 68, 46-60.

Santiago, C. D., Wadsworth, M. E., \& Stump, J. (2011). Socioeconomic status, neighborhood
Depression and Stress, Autism and Family Income

disadvantage, and poverty-related stress: Prospective effects on psychological syndromes among diverse low-income families. Journal of Economic Psychology, 32, 218-230.

Shamsuddin, K., Fadzil, F., Wan Ismalil, W. S., Omar, K., Muhammad, N. A., Jaffar, A., ... Mahadevan, R. (2013). Correlates of depression, anxiety and stress among Malaysian university students. Asian Journal of Psychiatry. Retrieved from http://dx.doi.org/10.1016/j.ajp.2013.01.014

Sobel, M. E., (1982). Asymptotic confidence intervals for indirect effects in structural equation models. In S. Leinhardt (Ed.), Sociological Methodology 1982 (pp. 290-312). Washington, DC: American Sociological Association.

Tsai, W. C., Tsai, J. L., \& Shyu, Y. I. L. (2008). Integrating the nurturer-trainer roles: Parental and behavior/symptom management processes for mothers of children with autism. Social Science \& Medicine, 67, 1798-1806.

Turney, K. (2012). Pathways of disadvantage: Explaining the relationship between maternal depression and children's problem behaviors. Social Science Research, 41, 1546-1564.

Wadsworth, M. E., Raviv, T., Reinhard, C., Wolff, B., Santiago, C. D., \& Einhorn, L. (2008). An indirect effects model of the association between poverty and child functioning: The role of children's poverty- related stress. Journal of Loss \& Trauma, 13, 156-185.

Young, A., Ruble, L., \& McGrew, J. (2009). Public vs. private insurance: Cost, use, accessibility, and outcomes of services for children with autism spectrum disorders. Research in Autism Spectrum Disorders, 3, 1023-1033.

Yozwiak, J. A. (2010). Postpartum depression and adolescent mothers: a review of assessment and treatment approaches. Journal of Pediatric and Adolescent Gynecology, 23, 172-178. 


\section{Appendix A}

Figure 1:model of mediation effect of family income on the relationship between depression and stress in mothers and the severity of autism among children

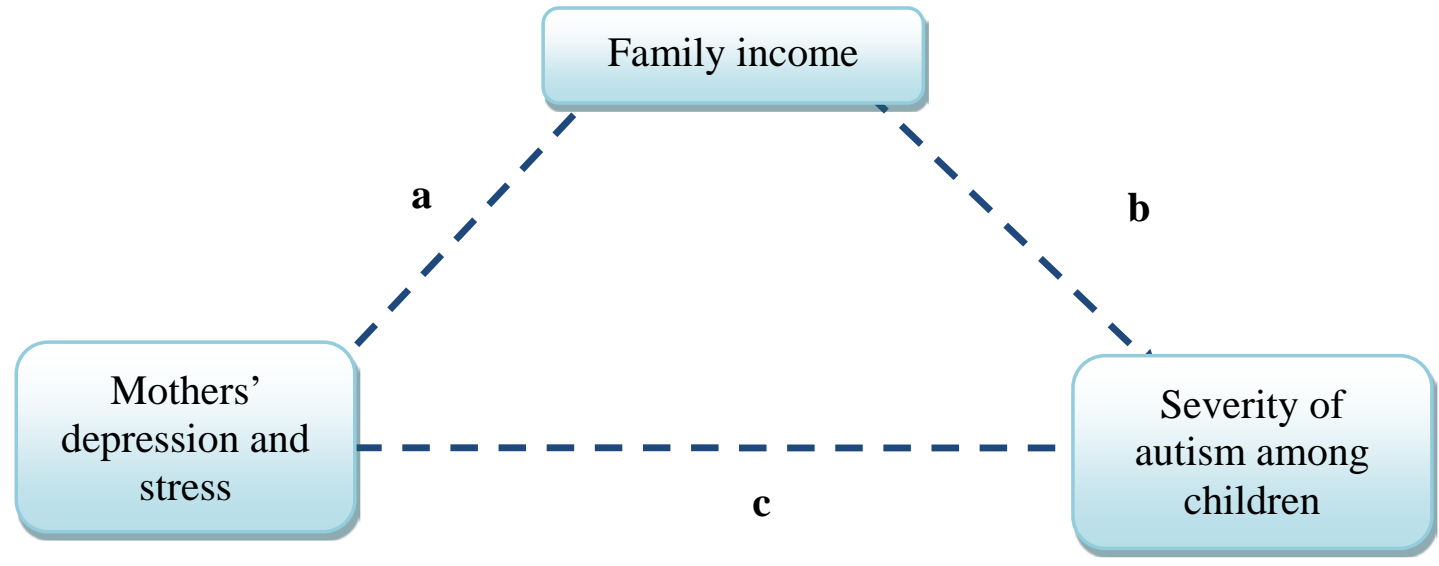

\section{Appendix B}

Table 1. Pearson Correlation test performed on depression and stress-severity of autism

\begin{tabular}{cccc}
\hline Model & & Depression and stress & Severity of autism \\
\hline \multirow{2}{*}{ Depression and stress } & Correlation coefficient & 1.000 & $0.809^{* *}$ \\
\cline { 2 - 4 } & Sig.(2-tailed) & - & 0.000 \\
\hline \multirow{2}{*}{ Severity of autism } & Correlation coefficient & $0.809^{* *}$ & 1.000 \\
\cline { 2 - 4 } & Sig.(2-tailed) & 0.000 & - \\
\hline
\end{tabular}

Table 2. Pearson's Correlation test performed between Family Income and Depression and stress among Mothers

\begin{tabular}{llcc}
\hline Variable & No & Pearson’s value & Sig \\
\hline Family Income- Mother's Depression & 250 & $-0.584^{* *}$ & 0.000 \\
\hline Family Income- Mother's Stress & 250 & $-0.560^{* *}$ & 0.000 \\
\hline
\end{tabular}

Table 3. Pearson‘s Correlation test performed between Family Income and Severity of Autism among Children

\begin{tabular}{cccc}
\hline Model & & Family income & Severity of autism \\
\hline \multirow{2}{*}{ Family income } & Correlation coefficient & 1.000 & $-0.606^{* *}$ \\
\cline { 2 - 4 } & Sig.(2-tailed) & - & 0.000 \\
\hline \multirow{2}{*}{ Severity of autism } & Correlation coefficient & $-0.606^{* *}$ & 1.000 \\
\cline { 2 - 4 } & Sig.(2-tailed) & 0.000 & - \\
\hline
\end{tabular}

Ч | Athari, Ghaedi, \& Mohd Kosnin (2013) | int.j.psychol.res. 6(2) | PP. 98 - 106 | 
R E S E A R C H

Table 4. Regression test on relationship between mothers' depression and stress, severity of autism among children, and family income

\begin{tabular}{|c|c|c|c|c|c|c|}
\hline Model & Variable & $\begin{array}{l}\text { Unstandardized } \\
\text { Coefficients }(\beta)\end{array}$ & $\begin{array}{c}\text { Unstandardized } \\
\text { Coefficients (Std. } \\
\text { Error) }\end{array}$ & $\begin{array}{c}\text { Standardized } \\
\text { Coefficients } \\
(\beta)\end{array}$ & $\mathrm{t}$ & Sig. \\
\hline \multirow{2}{*}{$\begin{array}{c}\text { Depression } \\
\text { and stress- } \\
\text { severity of } \\
\text { autism }\end{array}$} & Constant & 1.241 & 0.077 & - & 16.025 & 0.000 \\
\hline & $\begin{array}{c}\text { Depression } \\
\text { and stress }\end{array}$ & 0.895 & 0.039 & 0.938 & 23.206 & 0.000 \\
\hline \multirow{2}{*}{$\begin{array}{l}\text { Depression } \\
\text { and stress- } \\
\text { family } \\
\text { income }\end{array}$} & Constant & 3.011 & 0.180 & - & 16.716 & 0.000 \\
\hline & $\begin{array}{c}\text { Depression } \\
\text { and stress }\end{array}$ & -0.591 & 0.090 & -0.610 & -6.584 & 0.000 \\
\hline \multirow{2}{*}{$\begin{array}{l}\text { Family } \\
\text { income- } \\
\text { severity of } \\
\text { autism }\end{array}$} & Constant & 4.067 & 0.187 & - & 21.746 & 0.000 \\
\hline & $\begin{array}{l}\text { Family } \\
\text { income }\end{array}$ & -0.611 & 0.091 & -0.620 & -6.746 & 0.000 \\
\hline
\end{tabular}

| Athari, Ghaedi, \& Mohd Kosnin (2013) | int.j.psychol.res. 6(2) | PP. 98 - 106 | 